Volumen XXI, número 2,

Julio-diciembre de 2021.

Recibido: 6 de julio de 2021.

Aprobado: 29 de octubre de 2021.

\title{
Planeación transfronteriza y movilidad en la región Matamoros- Brownsville (RMB): ¿de los espacios de flujo a los espacios de lugar?*
}

\section{Cross-border planning and mobility in the Matamoros-Brownsville (RMB) region: from spaces of flow to spaces of place?}

\author{
Arturo José de las Fuentes Hernández ${ }^{*}$ \\ Universidad Nacional Autónoma de México (UNAM), México. \\ Sergio Peña ${ }^{* * *}$ \\ El Colegio de la Frontera Norte (COLEF), México.
}

\begin{abstract}
Resumen
El objetivo de este artículo es analizar la planeación transfronteriza enfocada en la movilidad en la región Matamoros-Brownsville (RMB), como un caso de éxito, y a través de este reflexionar sobre los procesos de planeación urbano-transfronteriza que se implementaron. El documento pone a prueba la hipótesis de que la movilidad transfronteriza en la RMB no solamente se enfoca en los espacios de flujo que facilitan los cruces de mercancías y personas, sino también en los espacios de lugar que generan una identidad colectiva y arraigo al lugar. Los dos estudios de caso que se abordan son la relocalización de las vías del ferrocarril y la creación del Centro Cultural Binacional (CeCuBi). El proceso de planeación para el Proyecto Ferroviario se inició en 2001 y entró en operaciones en agosto de 2015,
\end{abstract}

\footnotetext{
${ }^{*}$ El presente artículo es una versión revisada y actualizada del trabajo final que presentó A.J.de las Fuentes en la especialidad de Ciudades del Siglo XXI dirigido por el Dr. Sergio Peña.

${ }^{*}$ Licenciado en Economía, Universidad Nacional Autónoma de México (UNAM). Maestro en Planeación de Ciudades, Escuela de Administración Pública, San Diego State University. Doctor en Ciencias Políticas y Sociales, UNAM. Correo electrónico: arturo@ crucesypuentesinternacionales.com, ORCID: 0000-0002-82466298.

${ }^{* * * *}$ Licenciado en Historia, UNAM. Maestría en Relaciones Internacionales y Doctor en Planeación Urbana y Regional, The Florida State University. Profesor de El Colegio de la Frontera Norte (COLEF). Correo electrónico: spena@colef.mx ORCID: 0000-0002-9505-4057
}

Cómo citar este artículo: de las Fuentes, Arturo y Peña, S. (2021). Planeación transfronteriza y movilidad en la región MatamorosBrownsville (RMB): ¿de los espacios de flujo a los espacios de lugar? Si Somos Americanos. Revista de Estudios Transfronterizos, 21(2), 38-69. doi: 10.4067/S0719-09482021000200038 
mientras que la segunda fase del proyecto, el $\mathrm{CeCuBi}$, comenzó su etapa de construcción en agosto de 2021.

Palabras clave: Movilidad fronteriza, planeación, infraestructura binacional, espacios de flujos, espacios de lugar

\begin{abstract}
The objective of this article is to analyze the issue of cross-border planning initiatives focused on mobility in the Matamoros-Brownsville (RMB) region, as a case of success, and through this to reflect on the urban-transboundary planning processes that have been implemented. The document tests the hypothesis that transboundary mobility in the RMB not only focuses on the spaces of flow that facilitate the crossings of goods and people, but also on the spaces of place that generate a collective identity and roots to such places. The two case studies addressed are the relocation of the railway tracks and the creation of the Binational Cultural Center $(\mathrm{CeCuBi})$. The planning process for the Railway Project began in 2001 and operations were initiated in August 2015, while the second phase of the project, the $\mathrm{CeCuBi}$, began its construction phase in August 2021.
\end{abstract}

Keywords: Border mobility, planning, binational infrastructure, spaces of flows, spaces of place

\title{
Introducción
}

La movilidad transfronteriza es un tema importante en la agenda bilateral México-Estados Unidos; particularmente es un problema de suma importancia tanto para las empresas locales, así como también para los corporativos trasnacionales y el esquema de producción just-intime de la industria maquiladora. Por supuesto que también para los habitantes que tienen conexiones familiares o que van de compras, de trabajo, o simplemente de paseo. Aunado a esto, la frontera cada vez es más restrictiva y el espacio fronterizo cada vez es más intimidatorio con la construcción de vallas o muros; en otras palabras, la función sine qua non de la línea internacional de "diferenciar" y separar (Newman, 2006) entre los que pertenecen a ese territorio y los que no, se hace presente de manera física y material.

Además de los problemas en la movilidad transfronteriza, también las ciudades de la frontera tienen el reto de mejorar la movilidad intraurbana. Ambos tipos de movilidad son claves para el desarrollo económico y social de las ciudades fronterizas. Las ciudades mexicanas en la frontera norte en las décadas de 1980 a 2000 experimentaron las tasas más altas de crecimiento poblacional, entre ellas la ciudad de Matamoros, Tamaulipas, que es el estudio de caso del presente artículo, como se puede apreciar en la tabla siguiente: 
Tabla 1: Población y tasas de crecimiento en Matamoros

\begin{tabular}{c|cc}
\hline Año & Población & $\begin{array}{c}\text { Tasa promedio de } \\
\text { crecimiento }\end{array}$ \\
\hline $\mathbf{1 9 8 0}$ & 238.840 & base \\
\hline $\mathbf{1 9 9 0}$ & 303.293 & 0,027 \\
\hline $\mathbf{2 0 0 0}$ & 418.141 & 0,038 \\
\hline $\mathbf{2 0 1 0}$ & 489.193 & 0,017 \\
\hline $\mathbf{2 0 2 0}$ & 541.979 & 0,011 \\
\hline
\end{tabular}

Fuente: Censos de población y vivienda (Instituto Nacional de Estadísticas y Geografía [INEGI])

Este crecimiento poblacional, en gran medida causado por la migración, ha rebasado la capacidad de la infraestructura vial, dado que las ciudades tienen una de las tasas de motorización más altas y en gran medida dependen del transporte privado (Trejo, 2013). Por último, el crecimiento de la mancha urbana ha generado una incompatibilidad entre los usos de suelo actuales y la nueva estructura urbana; es decir, infraestructuras (p. ej. vías de ferrocarril) que cuando se planificaron a inicios del siglo XX se encontraban en la periferia, actualmente forman parte del centro de la ciudad (Alarcón, 2000).

En razón de lo anterior, este texto tiene el objetivo de analizar los procesos de planeación enfocada en la movilidad en la región Matamoros-Brownsville (RMB), considerada como un caso de éxito, que pudiera ser replicado en otras zonas de la frontera México-Estados Unidos, donde existen conurbaciones transfronterizas. El tema de la movilidad y su planificación es complejo, ya que involucra una multiplicidad de escalas las cuales aumentan conforme la dimensión del proyecto.

En el caso de la frontera norte de México, en general, pero en particular en la RMB, se hace necesario tener en consideración otras escalas; por ejemplo, la binacional y la transfronteriza (Alegría, 1992). Estas escalas adicionan una multiplicidad de agentes, instituciones, intereses, entre otras cosas, que la hacen más compleja y representan un gran reto. Considerando la complejidad institucional, los proyectos transfronterizos toman una cantidad importante de tiempo en desarrollarse, por lo que no es algo fuera de lo común que un proyecto tome entre 10 y 20 años en ejecutarse, desde su concepción hasta la implementación (Peña, 2021).

En este artículo se analizan dos casos de estudio. El primero es el de la relocalización de las vías del ferrocarril; el segundo, el proyecto del Centro Cultural Binacional (CeCuBi). Ambos casos permiten poner a prueba la hipótesis de que la planificación en la RMB se ha transformado de tener un enfoque meramente centrado en los espacios de flujos (de mercancías y personas) a un enfoque espacial de lugar que no solamente genera identidad, 
sino que constituye espacios de encuentro y de relaciones socioespaciales (Castells, 1989, 1996; Massey, 2005; Tuan, 1977), y que algunos autores lo definen como el espacio relacional (Harvey, 2006; Lefebvre, 1974).

El resto del artículo está dividido en cinco secciones. La primera es de índole contextual, en la que se explica la dinámica urbana y de desarrollo de la RMB, poniendo énfasis en los procesos de globalización. La segunda desarrolla un marco teórico para analizar la planificación transfronteriza, ligando los conceptos espaciales de flujo y lugar con la planeación en un contexto global. La siguiente discute la estrategia metodológica basada en un estudio de caso. Le siguen una discusión de resultados que documentan los procesos de planificación que se emplearon para los dos estudios que se analizan. El artículo cierra con conclusiones y reflexiones finales.

\section{Contexto de desarrollo urbano y económico de la RMB}

\section{El crecimiento económico a partir del Programa de Industrialización Fronteriza (PIF)}

La generación de sistemas urbanos transnacionales es, en parte, resultado de una estructura organizativa de operaciones transfronterizas. Un ejemplo de este tipo de sistemas lo constituyen las ciudades de la frontera México-Estados Unidos, las cuales han experimentado, desde la década de 1960, un proceso de transformación gracias a la generación de sistemas de producción compartidos. Al respecto, la instalación de empresas maquiladoras en el lado mexicano representó un detonante para la articulación de redes entre ciudades globales y los sistemas urbanos transnacionales (Staudt, Fuentes y MonarrezFragoso, 2010).

La inserción temprana de México en las cadenas globales de producción se dio a través del denominado Programa de Industrialización Fronteriza (PIF) en 1966, que implementó la subcontratación de procesos industriales (IMEF, 1986), promoviendo con ello el rápido desarrollo de la frontera norte de nuestro país, en un contexto en el que las economías capitalistas avanzadas dirigieron sus esfuerzos hacia la búsqueda de desarrollo tecnológico para racionalizar la producción, bajar costos y crear nuevos mercados de competencia, en atención al panorama de la crisis del modelo capitalista, derivada del agotamiento del patrón de acumulación fordista, y que se reflejó en un estancamiento de la productividad y de las ganancias.

Se dio, entonces, una especialización de la actividad económica de ensamblaje y la inversión en la industria maquiladora aumentó en la frontera norte de México, donde algunas ciudades se convirtieron en puntos estratégicos para la localización de las empresas maquiladoras, debido a las ventajas comparativas y competitivas que ofrecían para los procesos de producción (Alarcón, 2000; Alegría, 1992). 
En el caso de la ciudad de Matamoros, situada en el estado de Tamaulipas, objeto de estudio de la presente investigación, su crecimiento económico y urbano tuvo un auge en la década de 1970 en este contexto de globalización y generación de sistemas urbanos transnacionales expresado a través del PIF, gracias al cual esta urbe se convirtió en la tercera localidad maquiladora de la frontera y sus primeras plantas se enfocaron en el ensamble de electrónicos. En 1975 se reportaron un total de 9.778 empleos en la maquiladora, número que representaba el 14,5\% del total en México; para 1990, el empleo creció en términos absolutos casi cuatro veces a 38.132, pero en términos relativos disminuyó su participación a 8,8\% del total (los cálculos se hicieron basados en datos de Lorey [1993]). Para el 2020, el empleo en la maquiladora registró un total de 61.525 plazas y la participación relativa fue de 2,2\% (INEGI, 2020)

La transformación de la economía de Matamoros (al igual que la de todas las ciudades de la frontera norte) en una de exportación ejerció una fuerte influencia en su crecimiento urbano. Para la década de 1990 era reconocida como la ciudad donde se pagaban los salarios más altos dentro de la industria maquiladora (Quintero y De la O, 1995), y registraba un incremento en el número de empleos. Todo esto trajo como consecuencia la modificación del desarrollo urbano para atender la instalación de los nuevos trabajadores.

La firma y entrada en vigor del Tratado de Libre Comercio de América del Norte (TLCAN) en 1994 favoreció el clima para la instalación de un mayor número de maquiladoras en la ciudad, haciendo un contraste entre la economía cerrada producto del modelo económico de sustitución de importaciones, que dominó durante la mayor parte del siglo XX, y la economía que generó la apertura comercial con el TLCAN.

A partir de ese momento, y durante las últimas décadas, la actividad económica en Matamoros ha ido en aumento, principalmente en el sector secundario y terciario. Para 1999, el 54,4 \% de la población económicamente activa (PEA) se concentró en el sector terciario, el $44,7 \%$ en el sector secundario y tan solo un $0,9 \%$ en el primario. Dentro del sector secundario, el 37,3\% de la fuerza laboral se empleó en la industria maquiladora, desarrollada por la inversión de compañías estadounidenses (Quintero, 2005). Para el 2010, la PEA constituyó el 41,6\% del total de la población del Municipio de Matamoros, siguiendo una tendencia de incremento y distribución similar para las actividades secundarias y terciarias, con base en la localización de los grandes centros de la industria maquiladora (Alarcón, 2000).

\section{El desarrollo urbano y su problemática}

Matamoros, como la mayoría de las ciudades fronterizas, experimentó un crecimiento poblacional acelerado sin precedentes como se ve reflejado en la tabla 1. Las tasas de crecimiento promedio por año desde 1990 hasta 2000 fue la más alta, alcanzando el 3,8 \%. Posterior al 2000, las tasas de crecimiento han disminuido. Lo importante a resaltar es que de 1980 a 2020 la población se ha incrementado poco más del doble. El crecimiento poblacional ha sido un reto, ya que las finanzas públicas del país en 1980 enfrentaron una 
crisis severa que afectó los presupuestos de los municipios, los cuales no tenían la capacidad para satisfacer la demanda de servicios básicos como agua, drenaje, alcantarillado, etc. (Aspe, 1993; Garza, 2005).

Algunos autores (Guillén, 1995; Peña, 2005) señalan que el desarrollo de la frontera norte es una paradoja, ya que de manera simultánea presenta altas tasas de crecimiento económico y altas tasas de rezago en materia de infraestructura y servicios públicos. El crecimiento de Matamoros, al igual que el de otras ciudades de la frontera, se dio de manera desordenada, acompañado de una falta de reacción por parte de las autoridades para proporcionar los servicios básicos para la población. Por ejemplo, en 1990 se registraron 300 colonias que no contaban con los servicios básicos (Quintero, 2005). En las dos últimas décadas, la brecha de acceso a servicios se ha cerrado. En la actualidad existe un stock de vivienda de 133. 116 casas particulares habitadas, entre las cuales el $94 \%$ cuenta con energía eléctrica, el $91 \%$ dispone de agua entubada y el $88 \%$ posee drenaje (Instituto Municipal de Planeación de Matamoros, 2013-2016), cuya distribución se puede observar gráficamente en la figura 1.

A lo anteriormente descrito, se debe sumar otro factor: las antiguas vías del ferrocarril quedaron en medio de la ciudad, lo que contribuyó a que los flujos comerciales y el tráfico local fueran más lentos, lo que propició un aumento de inseguridad en las áreas peatonales, disminuyendo la calidad de vida de la población al formarse una barrera que dividía la ciudad en dos y dificultaba el traslado de los pobladores (ver figura 1).

La demanda de infraestructura vial y la oferta de esta, a partir de $1980 \mathrm{y}$ hasta la fecha, no han crecido de manera paralela; la brecha entre una y otra se ha incrementado. A ello se debe sumar una creciente interdependencia entre las ciudades fronterizas, acompañadas de dinámicas transfronterizas propias de cada región. Recordemos que Brownsville y Matamoros forman parte de las denominadas ciudades gemelas de la frontera MéxicoEstados Unidos, entendidas estas como ciudades localizadas a ambos lados de una frontera internacional, cuyas características van desde el continuum urbano, las interacciones a través de la frontera y la asociación a una doble dimensión nacional y transnacional (Alegría, 2009).

Las características definitorias incluyen, por supuesto, una constante movilidad y la generación de infraestructura binacional para atender las dinámicas transfronterizas (entre ellas, cruces y puentes internacionales). Sin embargo, si bien es cierto que ambas ciudades mantuvieron un rápido crecimiento urbano, industrial y demográfico durante la segunda mitad del siglo XX, sobre todo en el caso de Matamoros, este dinamismo sobrepasó la capacidad de planificar y gestionar adecuadamente el ordenamiento urbano y territorial.

Por ende, el desarrollo urbano presenta problemas serios de movilidad para ambos lados de la frontera. Para la primera década del siglo XXI, en promedio atravesaron, diariamente, 65 mil vehículos las vías del ferrocarril por medio de quince cruceros en la ciudad de Brownsville, entre ellos autobuses escolares, lo que generó serios problemas viales y de seguridad tanto para conductores como para peatones. 
En el municipio de Matamoros se dio un fenómeno similar, en cuanto a los riesgos derivados de los problemas de movilidad: a través de nueve cruceros conflictivos con aforos de entre 23 mil vehículos diarios (el mayor) y 3.700 (el menor). En total, por los cuatro puentes vehiculares internacionales que unen a las ciudades de Matamoros, Tamaulipas, y Brownsville, Texas, cruzan más de cien mil vehículos diarios, que enfrentan los contratiempos que implican los congestionamientos por la deteriorada convivencia entre el ferrocarril y los vehículos automotores (De las Fuentes, 2007). A partir de estos factores surgió la necesidad de instrumentar un proyecto de infraestructura que permitiese, por un lado, reubicar los espacios de flujos y, por otro, generar espacios de lugar.

Figura 1: Plano de localización de los estudios de caso en Matamoros, Tamaulipas

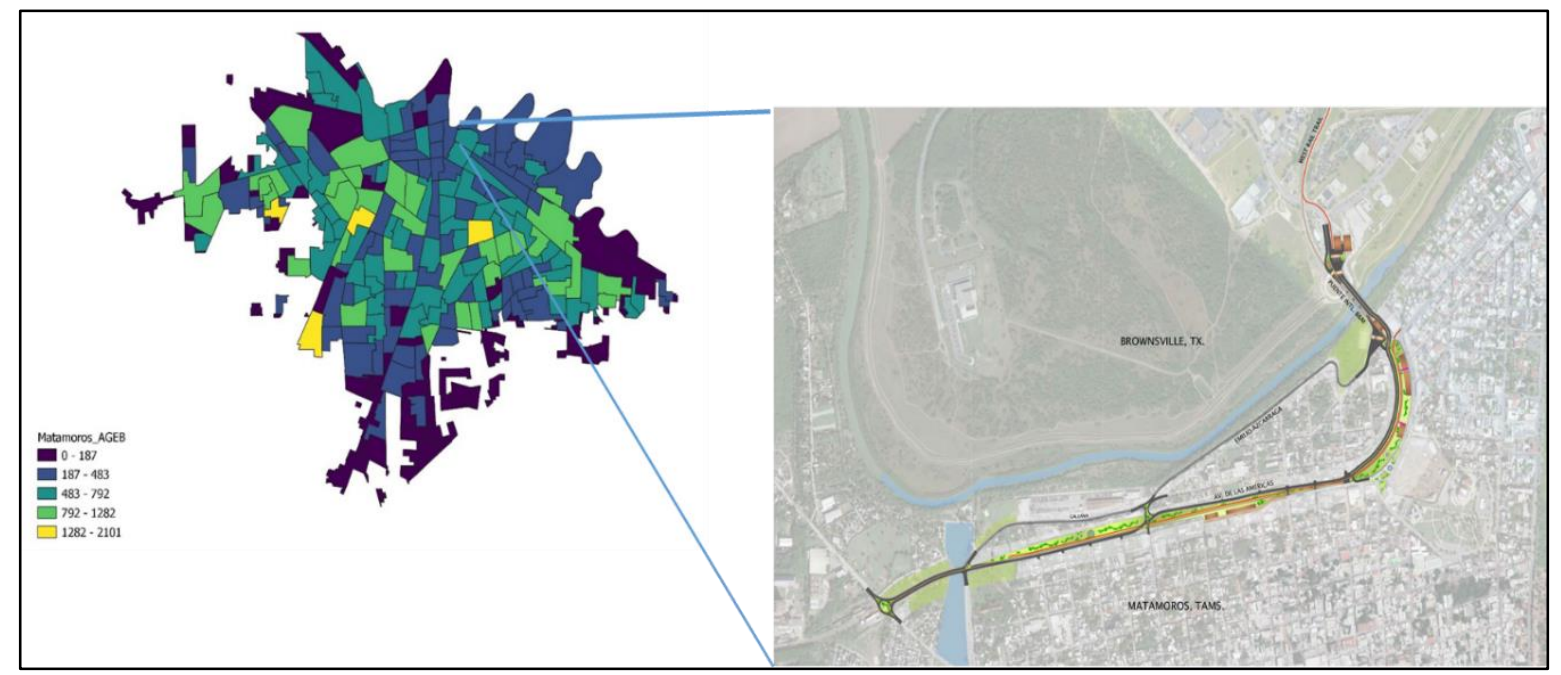

Fuente: elaboración propia basada en datos del Censo Nacional de Población y Vivienda 2010 (INEGI, 2020).

En lo que concierne al medioambiente, la problemática era de iguales dimensiones: las vías férreas ocasionaban problemas y riesgos ecológicos, tales como emisiones que afectan la calidad del aire, derramamientos de materiales tóxicos y químicos de alta peligrosidad, posibilidad de explosiones en áreas urbanas y residenciales, vibraciones adyacentes en edificios y casas, así como contaminación e inseguridad originadas por los frecuentes descarrilamientos, a veces cerca de zoológicos, estadios, edificios públicos y reservas hidráulicas, convirtiendo al tren en un generador de contaminación de residuos sólidos, del aire y auditiva, ya que pasaban hasta siete trenes diarios por la ciudad y debían accionar el silbato en cada cruce.

El proceso de planeación en su etapa inicial se enfocó en resolver la problemática de la movilidad y hacer más competitiva la zona para el intercambio comercial; sin embargo, con el mismo proceso de instrumentación, el equipo se dio cuenta de que había un problema de enfoque, ya que se consideraba únicamente su impacto en lo particular, sin una visión integral. La reflexión llevó a considerar que no se trataba únicamente de un proyecto específico de una sola ciudad dentro de la región fronteriza, sino que lo importante era el 
desarrollo de la zona y, para poder lograrlo, se hacía necesario formular un Plan Binacional con una visión que se proyectara hasta el año 2040.

De esta forma surgió un Plan de Infraestructura Estratégica que consideró, como resultado de la primera fase (el libramiento ferroviario), la necesidad de elaborar un proyecto integral que incorporara otros elementos que generaran una cohesión social entre ambas ciudades. A partir de ahí surgió la idea de también generar un proyecto que considerase los aspectos de corte económico, comercial, social, cultural, de desarrollo urbano y, por supuesto, de mejoramiento en la calidad de vida de las poblaciones involucradas, dando como resultado el CeCuBi.

\section{Marco teórico y conceptual}

En esta sección se desarrolla una matriz conceptual para entender los procesos de planificación transfronteriza de la movilidad. Dos líneas teóricas son consideradas como hilo conductor: una vertiente de teorías paraguas de índole epistemológico del espacio y otra vertiente de teorías intermedias basadas en la noción de ver la planificación transfronteriza como un régimen y proceso de cooperación para la producción de bienes colectivos (Peña, 2011).

\section{La globalización y las ciudades}

La globalización es uno de los grandes cambios que el capitalismo experimentó a partir de los setenta y que llegó a su zénit al final del siglo XX. Se puede hablar de varias causas y efectos, sin embargo, lo que es importante para este artículo es entender cómo se lleva a cabo un proceso de reestructuración del espacio y la transformación de las escalas de un esquema organizacional jerárquico a uno polimórfico y de redes, que algunos autores lo denominan relativización, salto de escalas, etc. (Laine, 2016; Swyngedouw, 2004). El entendimiento de este proceso de reestructuración es clave para poder explicar no solamente la transformación de la frontera norte de México, sino también la de las ciudades transfronterizas. Distintos autores concuerdan con el argumento que la globalización es una estrategia espacial para revitalizar el capitalismo y su función sine qua non es la de acumulación de capital (Castells, 1989; Harvey, 2006; Sassen, 2006).

Epistemológicamente hablando, se da un cambio paradigmático en cuanto a cómo entender el espacio y generar nuevas metodologías para abordarlo. El enfoque Estado-céntrico implicó caer en la trampa territorial (Agnew, 1994) que apunta a que toda explicación pone al Estado como el actor central y el espacio como un contenedor de procesos, a lo que se suma una organización espacial jerárquica con funciones bien marcadas y mutuamente excluyentes entre las diferentes escalas. La teoría crítica de la globalización y el espacio (Castells, 1989; Harvey, 2006; Sassen, 2001, 2006; Soja, 1989, 1996; Swyngedouw, 2004) cuestiona el 
enfoque Estado-céntrico, dado que las explicaciones sobre el proceso de reestructuración espacial producto de la globalización no son las más adecuadas.

Además, los trabajos de De Mattos (2010) son relevantes para entender el caso latinoamericano. Venegas (2019) también habla de una integración desde los márgenes en el caso de Chile y Argentina. Por su parte, los estudios de Staudt et al. (2010) son claves para entender la manera cómo la globalización se materializa en la frontera norte de México. Sassen $(2001,2006)$ argumenta que la globalización restructuró el capitalismo por medio de una nueva jerarquización espacial, donde las ciudades y lo local son tan importantes como la escala nacional y global.

La globalización restructura esa lógica escalar a algo amorfo, policéntrico, con múltiples nodos y centros (Agnew, 2015; Swyngedouw, 2004). Las fronteras se transforman de un concepto de línea horizontal que divide dos polígonos (Estados) a un puente que conecta y salta escalas (Álvarez, 2012). La representación cartográfica del mundo varía de una cartografía que divide el mundo en espacios discretos que conforman un rompecabezas de polígonos a una representación de múltiples conexiones que brincan las fronteras (Van Houtum, 2010). Nuevas epistemologías emergen para explicar el rol de nuevos actores, tales como las empresas transnacionales, empresarios locales, gobiernos locales -además del Estado- en los procesos de desfronterización; la frontera deja de ser un espacio marginal para convertirse en un "recurso" (Sohn, 2014) estratégico en la reconfiguración de las ciudades globales.

Manuel Castells (1989) fue uno de los primeros en apuntar que el capitalismo global se estaba restructurando no solo en la producción, sino también en la manera en cómo restructuraba el espacio y cómo lo conceptualizaba. El argumento se basa en una dicotomía para sustentar el cambio fundamental en la forma de concebir el espacio. La transición de espacio de lugar a espacio de flujo implica cambios fundamentales; un cambio de concepción de un espacio en estasis y fijo (lugar) a uno dinámico y en constante movimiento (flujos) con una multiplicidad de historias y diversidad de actores (Massey, 2005). Una transición de un espacio antropológico, que enfatizaba la identidad basada en una noción de pertenencia y arraigo (Creswell, 2015; Tuan, 1977), a un espacio de la hipermodernidad, que enfatiza la velocidad del movimiento (Virilio, 2006) y que no logra generar una identidad y se convierten en un “ no lugar" (Auge, 2008). Un argumento que es común encontrar sostiene que la globalización y los espacios de flujo son dos dimensiones que enmarcan la práctica de la planificación en las zonas fronterizas. Algunos autores (Blatter, 2004; Scott, 1999) han enfatizado que esta noción de espacios de flujo y lugar ofrece un marco teórico para comparar la forma en que los gobiernos locales y regionales en las zonas de frontera han respondido a la globalización a través de políticas de desterritorialización para hacerlas más funcionales e integrar las economías. 


\section{La teoría de la planeación y la producción de bienes colectivos transfronterizos}

En esta línea teórica, el enfoque se traslada a las teorías intermedias para explicar los procesos de planificación y cooperación, las que complementan a las teorías paraguas de cambio social y epistemologías del espacio. En este artículo partimos de la idea que la planificación transfronteriza es un proceso de formación de regímenes que implica la creación de mecanismos de cooperación y colaboración que con el paso del tiempo se institucionalizan (Peña, 2011; Lascurain, 2018). Acorde con Peña (2011), en el caso de la frontera MéxicoEstados Unidos se identifican tres tipos de regímenes: 1) distribución de recursos compartidos (p. ej. agua), 2) manejo de riesgos antropogénicos (p. ej. terrorismo) y naturales ('. ej. inundaciones), y 3) la producción de bienes colectivos (p. ej. infraestructura de movilidad como puentes). Ambos casos de estudio que se analizan en este artículo, se enmarcan en el tema de la producción de bienes de uso colectivo. Entonces, se hace necesario problematizar sobre los procesos de planificación de los bienes colectivos transfronterizos en el contexto de la globalización.

Una de las preguntas centrales es ¿de qué manera la planificación territorial responde a los retos que plantea la globalización a las ciudades? Entre los grandes retos está el cómo la ciudad puede no solamente ligarse a la globalidad, sino también, cómo puede explotar las oportunidades que esta genera (Friedmann, 2005; Hambleton y Gross, 2007).

En el mundo de la planificación, al igual que en el caso de la epistemología espacial, se da un cambio paradigmático de un enfoque euclidiano-racional a un enfoque relacional. El enfoque racional concibe el espacio como un rompecabezas a armar de manera funcional y donde el reto es poner las piezas en el lugar adecuado, basado en la idea de reducir la fricción de la distancia y mejorar la eficiencia del sistema. Por otro lado, el enfoque relacional del espacio se fundamenta en la noción básica de Lefebvre (1974) que considera el espacio como un constructo social que adquiere significado a partir de las relaciones sociales entre los diferentes actores; el poder y la forma como este se despliega -positiva o negativamenteson un factor explicativo clave.

El poder puede ser constructivo y emplearse en un esquema de juego de suma variable (en el que todos los actores se benefician, aunque de manera diferenciada) o en uno de juego de suma-cero (las ganancias de uno son las pérdidas del otro). Varios autores han enfatizado que la planeación en el mundo actual se basa en la noción de la "acción comunicativa" de Habermas, que sostiene que el diálogo honesto y la cooperación son fundamentales en la formación de una noción compartida de los problemas entre los actores, y que a la vez produce marcos de acción basados en reconocer la intersubjetividad e interdependencia de intereses (Allmendinger y Tewdwr-Jones, 2005; Healey, 1997; Innes y Booher, 2010).

La respuesta desde el mundo de la planificación fue la de replantear los procesos racionalistas de ligar medios y fines, con una dosis de la planificación en el mundo corporativo y de procesos colaborativos, dando como resultado el enfoque estratégico (Bryson, 2011; 
Kaufman y Jacobs, 1987). A fines de los ochenta y sobre todo en los noventa, la planificación estratégica fue el nuevo mantra de la planificación territorial. Uno de los atractivos de la planificación estratégica, para muchos actores, radicaba en que se adecuaba al paradigma de la gobernanza. Primero, era una manera de proponer nuevos procesos que ponían en el centro de la acción la eficacia y eficiencia de los resultados, adoptando algunas prácticas provenientes del sector corporativo (p. ej., el benchmarking, el análisis FODA, ${ }^{1}$ entre otros). Segundo, era un tipo de planificación que se adecuaba a la nueva filosofía neoliberal de hacer el gobierno más eficiente y facilitar la inversión privada en los asuntos públicos, adoptando una filosofía laissez-faire de desarrollo urbano. Tercero, los procesos jerárquicos de arriba hacia abajo abandonan el asiento del conductor y se convierten en un copiloto que facilita la toma de decisiones de múltiples actores que, en lugar de competir, cooperan para lograr metas comunes (Denhardt y Denhardt, 2003).

La planificación y la toma de decisiones dejan de ser un asunto solamente del gobierno y de expertos tecnócratas, y pasa a convertirse en un asunto de cooperación de múltiples actores en torno a un valor fundamental -desarrollar el espacio y aprovechar las oportunidades que la globalización ofrece (Healey, 2007). El meollo de la toma de decisiones es de qué manera explotar no solamente las ventajas comparativas (basadas en el diferencial de costos de producción), sino también la ventaja fija de la localización en función de la nueva jerarquía espacial de ciudades globales. La ciudad se reconceptualiza, dejando de ser un espacio donde habitan las personas y hay espacios de encuentro para convertirse en un objeto y una marca que hay que "vender" al mundo, donde además de la accesibilidad es importante tener una oferta cultural que atraiga no solo a turistas, sino también que constituya un polo de creación de empleos atractivos para las nuevas clases de jóvenes urbanos conocidos como yuppies (young urban profesionals).

Varias ciudades en México adoptaron la planeación estratégica como forma de desarrollar su crecimiento. En la frontera norte hay casos como el de Ciudad Juárez (Fuentes y Fuentes, 2004) que desarrolló un plan estratégico. En Tijuana por muchos años han promovido el lema de "Tijuana innovadora" como una forma de vender la ciudad y dando cuenta de cómo esta se adapta a la economía del conocimiento. En la frontera Tamaulipas-Texas, donde se ubica Matamoros, también se empleó el marketing territorial (Oliveras, 2015). El CeCuBi es una estrategia de cómo la ciudad de Matamoros reconoció que no solamente era importante el enfoque de flujos (cruces y vialidades), sino que también debía complementarse con una propuesta cultural desde un enfoque de lugar.

La gobernanza transfronteriza es otro tema que surge en este debate. El argumento central es que el modelo weberiano de gobernabilidad de índole jerárquico burocrático, de arriba hacia abajo, no es funcional en el contexto de la globalización, donde las escalas difusas hacen difícil que este modelo opere. Algunos autores proponen que la gobernanza multinivel ha remplazado el modelo weberiano (Brunet-Jailly, 2005; Hooghe y Marks, 2001; Lara y

\footnotetext{
${ }^{1}$ Fortalezas, oportunidades, debilidades y amenazas.
} 
Cerqueira, 2017). Esta gobernanza multinivel se basa en involucrar una constelación amplia de actores gubernamentales y no gubernamentales organizados en red. De esta forma, diferentes actores comandan diversos recursos y poder para que puedan emplearse en función de lograr metas en común. El desarrollo de las infraestructuras de movilidad es un modelo que cada vez es más cercano a la gobernanza multinivel (Peña, 2021).

Esta discusión teórica deja en claro que los espacios de flujo si bien son relevantes en la explicación de la restructuración espacial de la globalización, son limitados en cuanto a explicar procesos de planificación en los que los espacios de lugar, primordialmente aquellos enfocados al consumo cultural, también juegan un rol importante (p. ej., Bilbao). Por lo tanto, se hace necesario problematizar ambos de manera conjunta. El tipo de infraestructuras y equipamiento que se producen son las evidencias empíricas y materiales más relevantes que existen como dato o hechos que permiten operacionalizar y poner a prueba la hipótesis previamente establecida. Los estudios de caso seleccionados son un insumo empírico para poner a prueba la hipótesis. Las infraestructuras asociadas con los espacios de flujo son aquellas que enfatizan y priorizan la movilidad (puentes, ferrocarriles, carreteras, aeropuertos, etc.), mientras que las infraestructuras de espacios de lugar tienen que ver con la cultura, identidad, arraigo, cohesión e integración social y calidad de vida (museos, parques, espacios de convivencia, participación social, etc.).

\section{Metodología}

Antes de entrar de lleno a discutir los procesos de planeación que se emplearon en la región es importante hacer una breve discusión sobre la metodología de la presente investigación. La metodología que se empleó para el artículo es de índole cualitativo, basado en estudios de caso y análisis de contenido. Según Yin (1994), los estudios de casos son apropiados cuando el análisis trata de explicar el quién, cómo y qué resultados se obtienen en un contexto en el cual el investigador no tiene la capacidad de conducir un experimento bajo condiciones de control. Con base en la clasificación de este autor de los estudios de caso, el artículo es un ejemplo de múltiples casos con múltiples unidades de análisis. Aquí se discuten dos proyectos que constituyen el estudio de caso: 1) un proyecto enfocado en la relocalización de las vías del ferrocarril en la periferia como un ejemplo de espacio de flujo. 2) El desarrollo del plan del CeCuBi como un ejemplo de espacio de lugar. Las unidades de análisis que se estudian son los procesos de planificación implementados y los aprendizajes colectivos que se generaron.

En lo que respecta a las fuentes de información, se trabajó con dos tipos: fuentes secundarias y fuentes primarias. Las primeras emplean datos producidos por diferentes entidades en ambos lados, como son los censos de población, datos producidos y sistematizados por autoridades municipales tales como el Instituto Municipal de Planeación de Matamoros y el Cameron County Regional Mobility Authority. Las segundas aportan datos claves para este artículo, provenientes de las minutas de las reuniones de los diferentes comités binacionales 
y los estudios llevados a cabo por la empresa consultora Cruces y Puentes Internacionales (De las Fuentes, 2021). A lo anterior hay que sumar las múltiples referencias bibliográficas correspondientes a la literatura especializada en el tema. En resumen, la presente información hace un proceso de triangulación de la información para dar mayor validez interna y externa a la presente investigación.

En lo que corresponde a la metodología de los procesos de instrumentación de un proyecto de infraestructura binacional, esta se realiza a lo largo de cuatro fases, que son las siguientes:

- Fase I; Planeación del proyecto y aprobación preliminar (factibilidad).

- Fase II: Revisión técnica de las dependencias (permiso presidencial y análisis costobeneficio).

- Fase III: Elaboración de proyecto ejecutivo, licitación y asignación del proyecto.

- Fase IV: Construcción e inicio de operación.

Figura 2: Las cuatro fases de instrumentación de un proyecto de infraestructura binacional

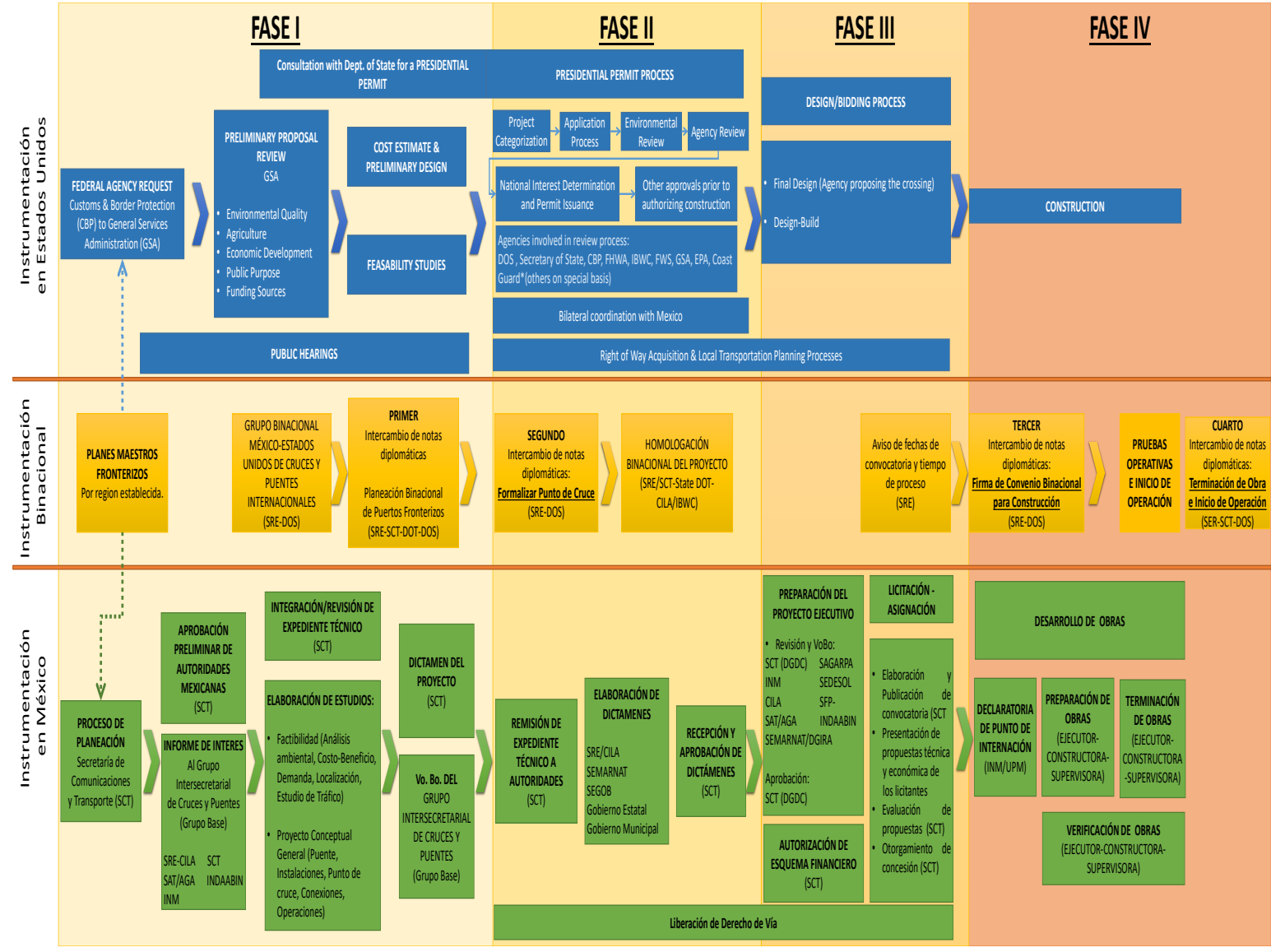

Fuente: NADBANK (2016). 
En la fase 1 de instrumentación en los proyectos de infraestructura binacional se desarrolla un análisis de factibilidad, que incluye los objetivos del proyecto, el análisis del punto de cruce, el análisis del impacto del proyecto en el resto del país, los impactos ambientales potenciales y las fuentes de financiamiento posibles. Esta primera fase concluye con una recomendación para proceder con la solicitud de permiso presidencial del lado estadounidense y define la dependencia federal que se encargará del proyecto. La selección de la dependencia líder será en función del tipo de proyecto.

Durante esta fase, también se conforma el Grupo Técnico Binacional, que será el foro de discusión y generación de acuerdos, integrado por las dependencias federales de ambos países, así como por los representantes del sector empresarial de los estados, municipios, condados o localidades. Su finalidad es crear consenso y generar acuerdos entre los participantes involucrados en una o más tareas dentro del proyecto para cumplir con sus objetivos, y generar transparencia y confianza entre los mismos participantes.

La fase 2 del proceso de instrumentación se efectúa de manera diferente en ambos lados (mexicano y estadounidense), ya que, si bien implica la revisión técnica de las dependencias federales, la manera de abordar el proceso con las dependencias es diversa. En el caso de Estados Unidos, esta etapa incluye la obtención del permiso presidencial y la revisión técnica de las dependencias, que involucra una revisión general del proyecto por todas las instancias gubernamentales competentes, y una evaluación del interés nacional en el proyecto. Del lado mexicano, no existe una autorización federal que agrupe todos los trámites, sino que se ve de manera separada con las diferentes dependencias a través de la Secretaría de Relaciones Exteriores.

La parte central de la fase 3 se refiere a la elaboración del Proyecto Ejecutivo, así como su autorización en ambos lados de la frontera y la entrega del mismo a las empresas constructoras. Esta fase es resultado de las dos anteriores, de la factibilidad del proyecto y de las autorizaciones en la etapa conceptual. Aquí se diseña el proyecto en detalle, que es resultado de la aprobación del proyecto conceptual por parte de la Comisión Internacional de Límites y Aguas (CILA) y su contraparte estadounidense, la Internacional Boundary and Water Commission (IBWC).

Finalmente, la cuarta fase, que corresponde a la construcción y al inicio de la operación, conlleva tiempos muy bien definidos, en los que están implicados, por una parte, las empresas constructoras que realizan el trabajo, y por otra, las instancias gubernamentales que llevan a cabo la obra, en cuyo margen de acción está el permitir el inicio de operaciones del nuevo cruce o puente internacional.

A lo largo de estas cuatro fases, el rol de la Coordinación Binacional descansa en llevar a cabo las negociaciones y la formulación de intereses comunes, asegurando así la adecuada comunicación y armonización bilateral en las distintas fases de la instrumentación de un proyecto de infraestructura binacional. 
En el caso del proyecto ferroviario Brownsville-Matamoros, el proceso se dio de la siguiente manera:

Figura 3: Las cuatro fases del proyecto ferroviario Brownsville-Matamoros

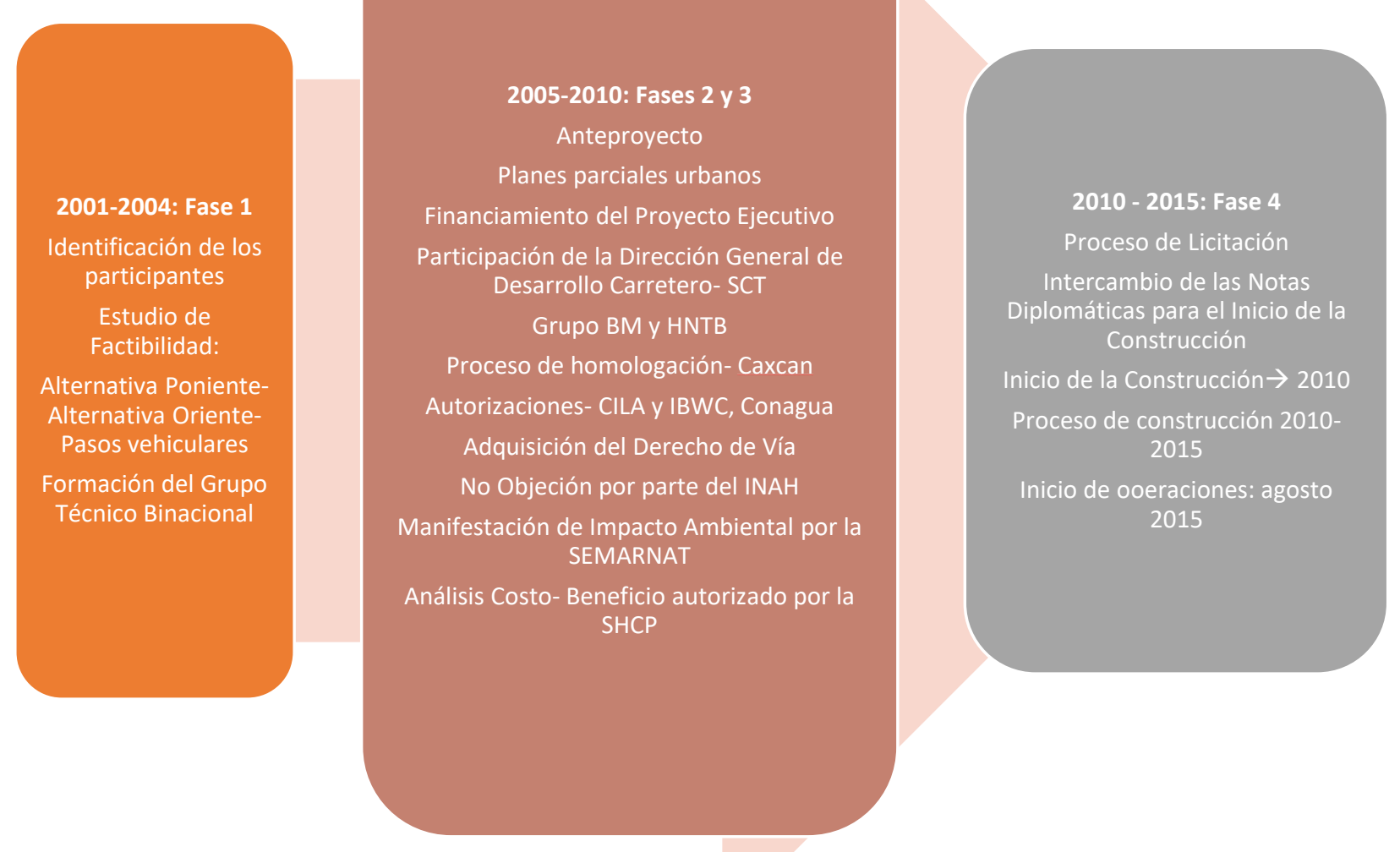

Fuente: elaboración propia.

\section{Los procesos de planificación transfronteriza en la RMB}

La planificación transfronteriza en la RMB en las últimas dos décadas se inició con la generación de un Plan de Instrumentación Estratégica (PIE), elaborado durante el segundo semestre de 2012, que fue el resultado de un proyecto preliminar, y a la vez paralelo: el Proyecto del Libramiento Ferroviario Brownsville-Matamoros, el cual se comenzó a instrumentar en 2001, y mediante el cual se detectó una serie de necesidades propias de la región binacional.

Inicialmente, el PIE solo consideró un proyecto ejecutivo con un fin específico (relocalizar las vías y mejorar la movilidad). Posteriormente, los objetivos del PIE se replantearon bajo 
una perspectiva integral, que apuntaba a que lo importante no era un proyecto en un sitio específico, sino considerar la región como un espacio integrado, no separado, y para poder desarrollarlo era necesario cambiar la visión de un PIE a un Plan Binacional con una visión que se proyectara hasta el 2040, año en que el proyecto ferroviario sería un instrumento o medio, y no el fin en sí mismo.

A partir de la identificación de las diferentes problemáticas en materia de desarrollo urbano en Matamoros, se planteó la interrogante de cómo poder desarrollar la región de manera integral, cuidando el desarrollo urbano, promoviendo un comercio más ágil entre los dos países y mejorando la calidad de vida de las poblaciones fronterizas.

Dada la caracterización binacional de la región, se tomaron en consideración los elementos de ambos lados de la frontera: por un lado, Brownsville es la sede y la ciudad más grande del Condado de Cameron (Cameron County). Este condado fronterizo está formado por las ciudades de Brownsville, Harlingen, La Feria, Los Fresnos, Palm Valley, Port Isabel, Rio Hondo y San Benito. El Condado de Cameron es en realidad una región de muchos contrastes, pero que hoy en día presenta un importante dinamismo económico. Tamaulipas, por su parte, es el estado fronterizo mexicano con más cruces internacionales -18 a lo largo de la frontera, desde Nuevo Laredo hasta Matamoros- y cuenta con una industria maquiladora altamente desarrollada, así como importantes yacimientos de petróleo, gas natural y gas de esquisto o gas shale.

En función de lo anterior, y con el fin de promover el desarrollo integral de la zona, se elaboró en 2012 el PIE del Condado de Cameron, Texas, y del Municipio de Matamoros, Tamaulipas, con el objetivo de contar con un instrumento que permitiera saber cuáles serían los proyectos que se implementarían hasta el año 2040 para lograr tener un impacto en el comercio entre México y Estados Unidos, y mejorar la calidad de vida de los habitantes de la región.

Básicamente, este PIE tuvo como objetivo integrar en forma coherente y lógica los Planes del Cameron County Regional Mobility Authority (CCRMA) a los planes, obras, programas y proyectos de infraestructura en suelo mexicano del Municipio de Matamoros, Tamaulipas. Los planes consideraron los de los tres niveles de gobierno (municipal, estatal y nacional), así como los corredores carreteros y los puentes internacionales actuales, los que están en construcción, los que están en proceso de gestión y aquellos que están por realizarse en un futuro próximo, con el fin de convertir a la región en el Centro Logístico Intermodal más moderno, eficiente y competitivo de la frontera México-Estados Unidos, sustentado en una visión que se proyectaba hasta el 2040.

A partir de lo anterior, el plan propuesto por los gobiernos locales definió las actividades propias del proyecto, así como las necesidades y prioridades de una zona específica para la promoción del desarrollo de la misma, por lo que sus objetivos fueron:

- Establecer la ruta crítica para la instrumentación del proyecto y/o de los proyectos a desarrollar. 
- Identificar los proyectos de largo alcance en la zona.

- Promover los proyectos e instrumentarlos.

- Competir con otros espacios internacionales que cruzan el comercio de la Costa Pacífico al Atlántico, como son el caso de Long Beach en Estados Unidos o el Canal de Panamá.

El desarrollo e implementación del PIE se conceptualizó por medio de la estrategia de aproximaciones sucesivas de Lindblom (1959), también conocido como planeación gradual, y que consiste en identificar las actividades propias de cada fase del proyecto de infraestructura binacional e implementarlas poco a poco, sin causar alteraciones en el esquema mismo de la instrumentación, continuando paso a paso hasta que se haya consolidado el anterior, permitiendo así un avance gradual y controlado del mismo.

\section{La planeación de los espacios de flujos en la RMB}

El alcance de este proceso incluye la concepción de la idea, la factibilidad, los estudios de seguimiento y avance, la gestión binacional, los acuerdos entre participantes, la resolución de conflictos, así como el Proyecto Ejecutivo hasta lograr la construcción de los proyectos. A la vez, se consideran elementos del impacto del proyecto relacionado con el desarrollo de la zona, incluyendo aspectos de corte económico, comercial, social, cultural, de desarrollo urbano y, por supuesto, de mejoramiento en la calidad de vida de las poblaciones involucradas.

En el caso del Municipio de Matamoros y el Condado de Cameron, se identificaron diez proyectos prioritarios:

- El proyecto ferroviario Brownsville-Matamoros

- El puente Ignacio Zaragoza-Los Veteranos (Los Tomates)

- Los accesos al puente Ignacio Zaragoza-Los Veteranos (Los Tomates)

- La concesión del puente B\&M

- La construcción de la Avenida de las Américas

- Brownsville East Loop

- El Museo del Ferrocarril

- West Parkway

- El puente Flor de Mayo

- El puente BND (Puerto de Brownsville)

Dichos proyectos se pueden observar en la figura 4: 
Figura 4: Plano de localización de proyectos del Plan de Instrumentación Estratégica (PIE)

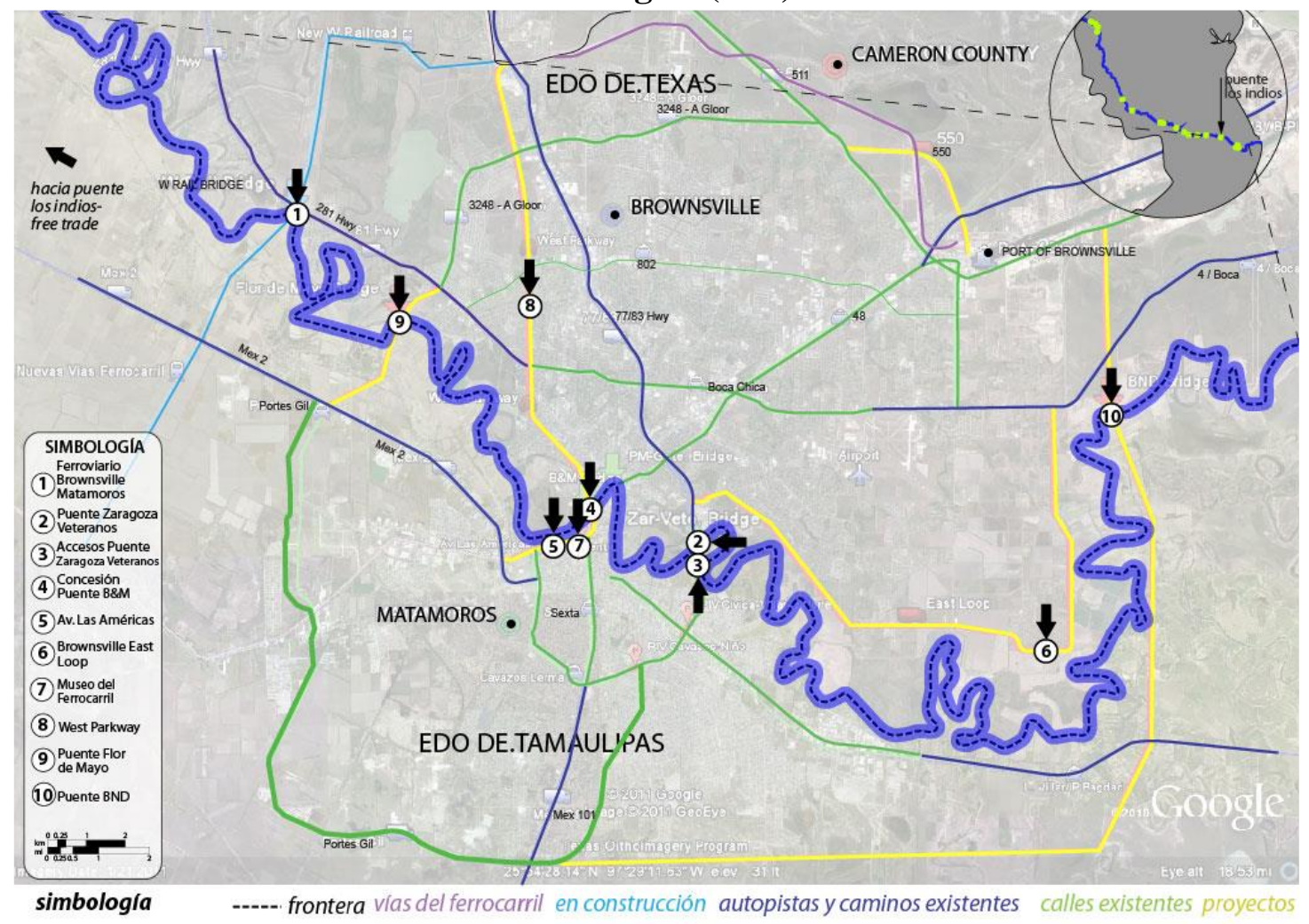

Fuente: Plan de Instrumentación Estratégica del Condado de Cameron, Texas, y el Municipio de Matamoros, Tamaulipas (2012).

De estos diez proyectos, cuatro ya se concluyeron (el proyecto Ferroviario BrownsvilleMatamoros, el puente Ignacio Zaragoza-Los Veteranos [Los Tomates], los accesos al puente Ignacio Zaragoza-Los Veteranos [Los Tomates] y el Museo del Ferrocarril), otros tres están en proceso de instrumentación (la concesión del puente B\&M, la Avenida de las Américas y el puente Flor de Mayo), mientras que el resto se encuentra "envisionado" o en fase de anteproyecto (West Parkway, Brownsville East Loop y puente BND [puerto de Brownsville]).

Como se mencionó anteriormente, en 2001 se inició formalmente la instrumentación del Proyecto Ferroviario Brownsville Matamoros, el primero en más de cien años en su tipo en la frontera México-Estados Unidos. El argumento central para implementar esta obra fue brindar una nueva oportunidad para mejorar el desarrollo urbano de las ciudades de Matamoros, Tamaulipas, y Brownsville, Texas, al eliminar el cruce del tren que se ubicaba en el centro de la ciudad.

De esta manera, en lado mexicano el proyecto consistió en:

- La construcción de una vía principal de 10,9 km de lado mexicano

- Nuevos patios ferroviarios con capacidad para más de 600 carros 
- La construcción de un paso vehicular en la carretera Reynosa-Matamoros

- La modificación del bordo de protección y la construcción del Puente Internacional con una longitud de $0,57 \mathrm{~km}$ (SCT, 2016)

Del lado estadounidense consistió en:

- Lo correspondiente del Puente Internacional

- La vía principal de $10 \mathrm{~km}$

- Los patios de olmito que fueron construidos hace más de 15 años, con 20,3 $\mathrm{km}$ (SCT, 2016)

Para su instrumentación se utilizó un enfoque pragmático de planeación y la adopción del método de aproximaciones sucesivas (Lindblom, 1959), con la finalidad de constituir los objetivos a corto plazo, reafirmar aquellos que son a mediano y largo plazo, y resolver los diferentes conflictos que van surgiendo en el proceso de instrumentación, desde una visión integral del mismo. Como se mencionó anteriormente, este método consiste básicamente en identificar las actividades propias de cada fase del proyecto de infraestructura binacional e implementarlas poco a poco, sin causar alteraciones en el esquema mismo de la instrumentación, continuando paso a paso hasta que se haya consolidado el anterior, permitiendo así un avance gradual y controlado del mismo.

Como parte de la participación social a lo largo del proceso, se conformó un Grupo Técnico Binacional, integrado por las dependencias participantes de ambos lados de la frontera en los diferentes niveles de gobierno, asociaciones, técnicos, las dos empresas ferroviarias (Union Pacific y Kansas City Southern de México) y el coordinador binacional, con la finalidad de dar seguimiento a los avances del proyecto en cada una de las etapas, promover una buena comunicación permanente, establecer la búsqueda de acuerdos entre los participantes, así como dotar de transparencia a los procesos, evaluando constantemente la instrumentación y reafirmando los objetivos y metas trazados para la consecución del mismo.

En función de todo lo anterior, se puede decir que el proceso de planeación desarrollado fue una combinación de los siguientes cuerpos teóricos: la teoría de la cooperación, la teoría de juegos, la teoría de la resolución de conflictos, todas ellas como marco para la negociación, combinadas con las aproximaciones sucesivas y la planeación estratégica. Todo esto llevó a que, en algunas fases del proyecto, la planeación e instrumentación se realizaron de manera simultánea, lo cual hizo más complejos los procesos, pero permitió desarrollar una visión integral de la zona, dotándola de herramientas para poder instrumentar varias fases a la vez.

Vale la pena mencionar que los participantes fueron cambiando y complementándose en función del tipo de tema que se fue tratando en el propio grupo técnico; sin embargo, hay que destacar que una de las funciones principales de este grupo consistió justamente, en conjunción con el proceso planteado, en llevar a cabo las negociaciones y la formulación de intereses comunes, asegurando así la adecuada comunicación y armonización bilateral en las distintas fases de la instrumentación de un proyecto de infraestructura binacional. 
La formación de dicho grupo técnico estuvo inspirada en la teoría de la resolución de conflictos como método, por lo que en la comunicación binacional institucional se han tenido resultados exitosos en lo que respecta a acelerar la velocidad de instrumentación de proyectos de infraestructura. En total, dicho grupo sesionó en 83 ocasiones entre el 2005 y el 2015, en las que se conciliaron los intereses de cada una de las agencias participantes y, al mismo tiempo, se dio forma a un grupo de especialistas con lazos fuertes de amistad y confianza.

Durante los diez años en que sesionó el grupo técnico, se promovió la comunicación entre las dependencias federales, estatales y locales de ambos países, con la finalidad de empatar reglas, normas y tiempos en los procesos, a fin de hacerle frente al reto burocrático, facilitando de esta forma una instrumentación más eficiente de las actividades propias de la misma.

Finalmente, el 6 de agosto a las 19:30 horas, cruzó el último tren de Matamoros a Brownsville por el puente Viejo Internacional, en tanto que, al día siguiente, a las 9:45 horas, circuló el primer tren de 112 carros desde Brownsville hacia Matamoros con destino a Monterrey, Nuevo León, cruzando el nuevo puente Ferroviario Internacional, el primero en construirse después de 105 años en la frontera México-Estados Unidos (figuras 5 y 6).

\section{Figura 5: Proyecto del Libramiento Ferroviario Brownsville- Matamoros (puente del lado estadounidense)}

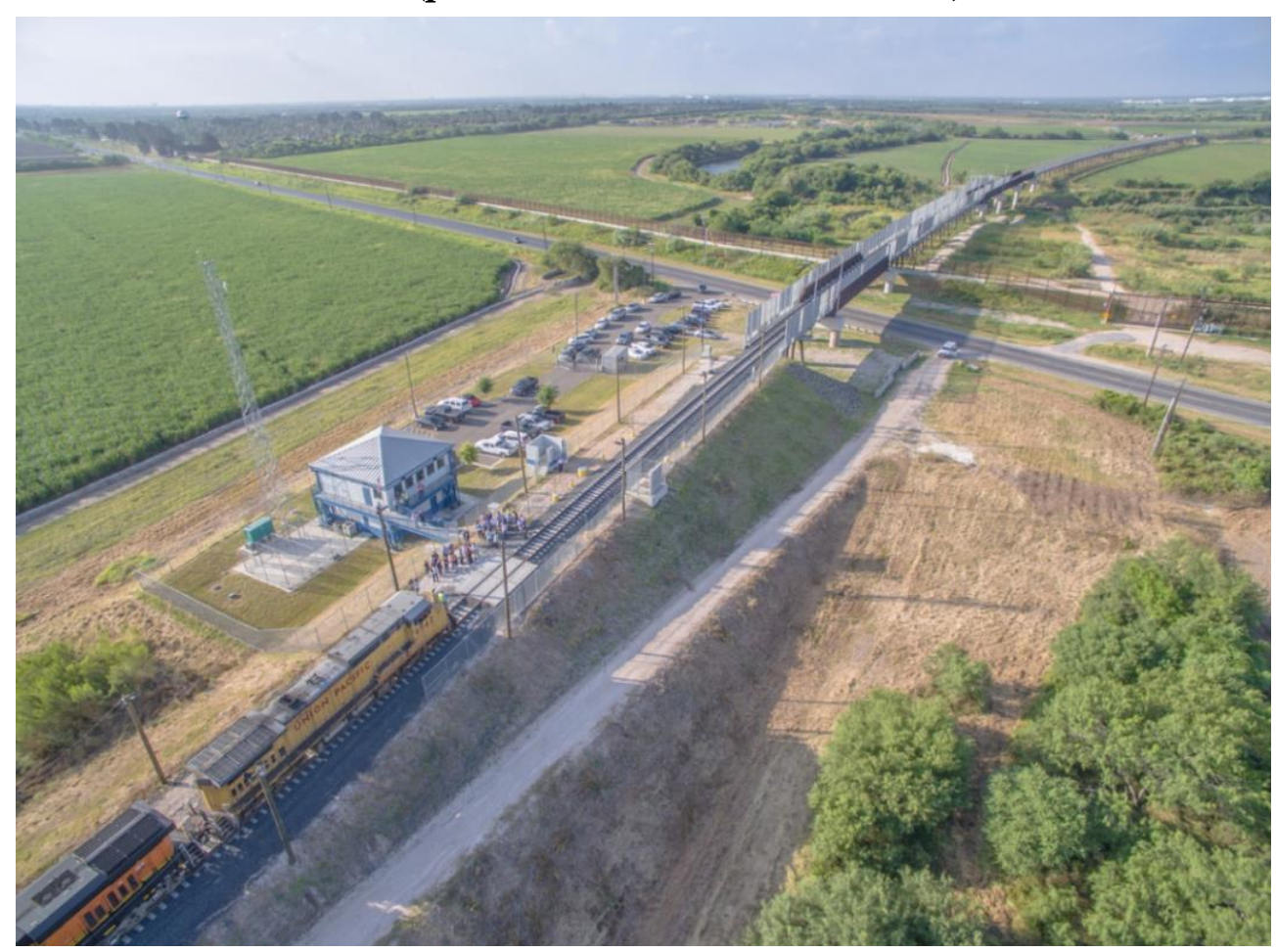

Fuente: elaboración del Condado de Cameron a partir del Proyecto del Libramiento Ferroviario Brownsville-Matamoros (2015). 


\section{Figura 6: Proyecto del Libramiento Ferroviario Brownsville- Matamoros (puente del lado mexicano)}

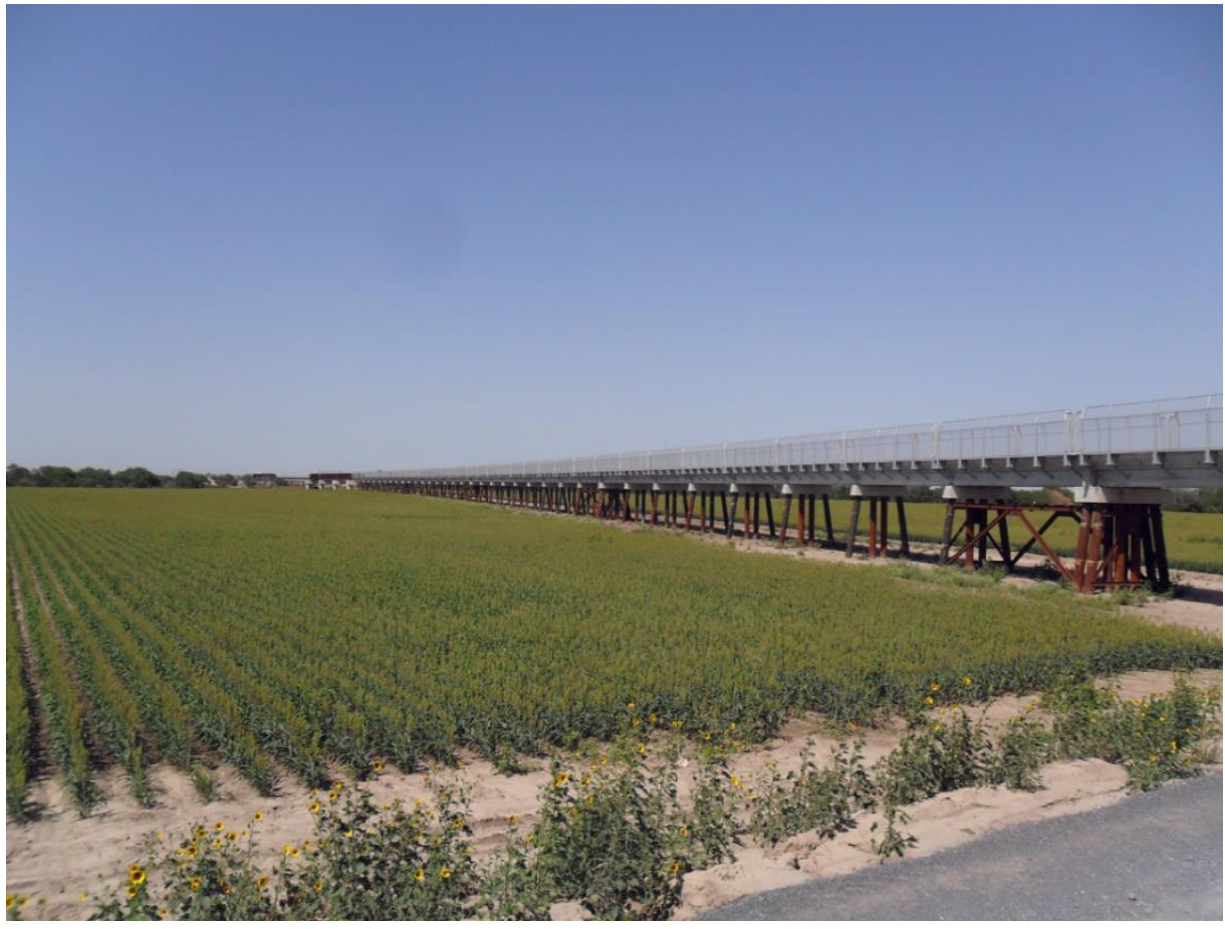

Fuente: elaboración del Condado de Cameron a partir del Proyecto del Libramiento Ferroviario Brownsville-Matamoros (2015).

De la planeación de los espacios de flujo a la planeación del espacio de lugar: El Centro Cultural Binacional (CeCuBi)

La conclusión exitosa del Proyecto Ferroviario Brownsville-Matamoros no solo permitió agilizar el comercio bilateral en la zona, sino también mejorar el ordenamiento urbano y territorial de estas ciudades fronterizas, optimizar la calidad de vida sus poblaciones, así como generar una visión a corto, mediano y largo plazo para promover el desarrollo integral de la zona y de la frontera México-Estados Unidos en general.

A partir de lo anterior, se visibilizó entonces un nuevo reto: transformar el espacio históricamente considerado de flujos, y enfocado en los cruces fronterizos, en un espacio binacional apto para las mismas dinámicas transfronterizas que se llevaban a cabo diariamente, y que provienen de una herencia histórica compartida, así como de los lazos que se han formado actualmente a partir de la dinámica de la integración regional. En otras palabras, concebir el espacio en su acepción relacional, vale decir, donde las relaciones sociales, las interacciones cotidianas y, sobre todo, lo identitario, arraigo al lugar y memoria histórica, son aspectos fundamentales (Tuan, 1977).

La transformación de este espacio ha dado como resultado, para estos últimos años, el proceso de planeación e instrumentación simultánea del Proyecto de ampliación y reconversión del puente internacional B\&M de ferroviario a vehicular, así como el parque 
lineal y las obras del CeCuBi en Matamoros, Tamaulipas, el cual incluye las siguientes acciones:

- El Proyecto de ampliación y reconversión del puente internacional B\&M de ferroviario a vehicular.

- La construcción de la Avenida de las Américas.

- El desarrollo (transformación en espacios de lugar) de los viejos patios ferroviarios que fueron transferidos de la empresa Kansas City Southern de México a Fonadin.

- La integración del actual Centro Histórico de Matamoros.

- La creación del Museo del Ferrocarril.

- La construcción de espacios recreativos y culturales.

- La construcción del nuevo consulado de Estados Unidos en Matamoros.

Para la ampliación del puente internacional, se habilitará el puente ferroviario que desocupó el tren para convertirlo en un cruce vehicular mediante la construcción de dos carriles que atiendan a los usuarios con dirección al sur, lo cual liberará el flujo en ambas direcciones y permitirá agilizar los cruces en la región. Se propone aquí la construcción de un corredor vial de aproximadamente 2,4 km de longitud, denominado Av. De las Américas, que sirva de acceso al puente internacional Brownsville-Matamoros (B\&M), en el que, también se aproveche el puente ferroviario internacional B\&M y el derecho de vías que quedan libres al reubicar el paso del ferrocarril fuera de la ciudad de Matamoros. El proyecto corre desde la Av. Primero de Mayo hasta el Cruce Internacional B\&M, dividido en tres tramos, tal como se exhibe en la figura 7:

Figura 7: Proyecto integral de la reconversión del Puente $B \& M$ de ferroviario a vehicular y la Avenida de las Américas

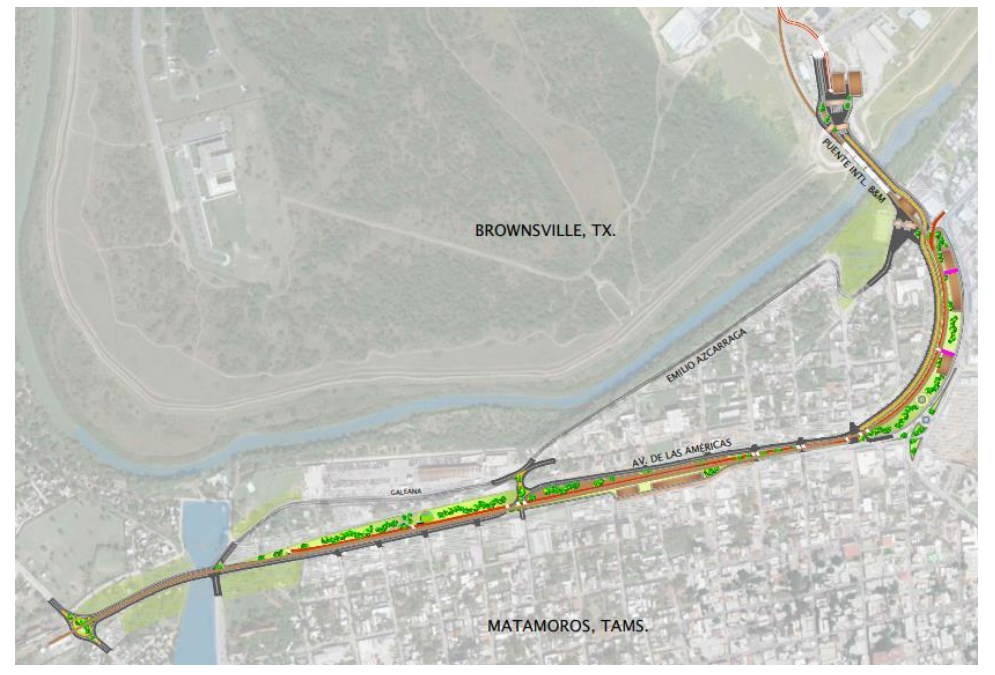

Fuente: Instituto Municipal de Planeación de Matamoros (2013-2016) y CeCuBi (2021). 
El proyecto incluye las siguientes obras:

- Entronque a nivel Av. Primero de Mayo

- Corredor de cuatro carriles de la Av. Primer de Mayo a la Calle Manuel Cavazos

- Puente Laguneta

- Entronque Manuel Cavazos

- Corredor de dos carriles de la calle Manuel Cavazos a la Calle Seis

- Entronque a nivel de la calle Catorce

- Entronque a nivel de la calle Seis

- Cruces a nivel de las calles Dieciséis, Ocho y Siete

- Reubicación de instalación eléctrica

- Drenaje pluvial

- Alumbrado

- Reposición de infraestructura

Por su parte, las obras culturales tienen como objetivo la integración del actual Centro Histórico de Matamoros, el Museo del Ferrocarril (ya concluido), la construcción de espacios recreativos y culturales, y la construcción del nuevo consulado de Estados Unidos en Matamoros (ya concluido). Para ello, las acciones contempladas incluyen las siguientes:

- Restauración de la estación (ya realizada, figura 8).

- Programa de colecciones para el museo. Se estudiará y resolverá el traslado de una locomotora que la Secretaría de Cultura Federal mediante el Centro Nacional para la Preservación del Patrimonio Cultural Ferrocarrilero entregará en comodato a Matamoros.

- Elaboración del Plan Integral por parte de la Secretaría de Cultura, que implica desarrollar los programas de contenido en el museo y determinar las funciones de los distintos componentes del centro cultural. 
Figura 8: Museo del Ferrocarril

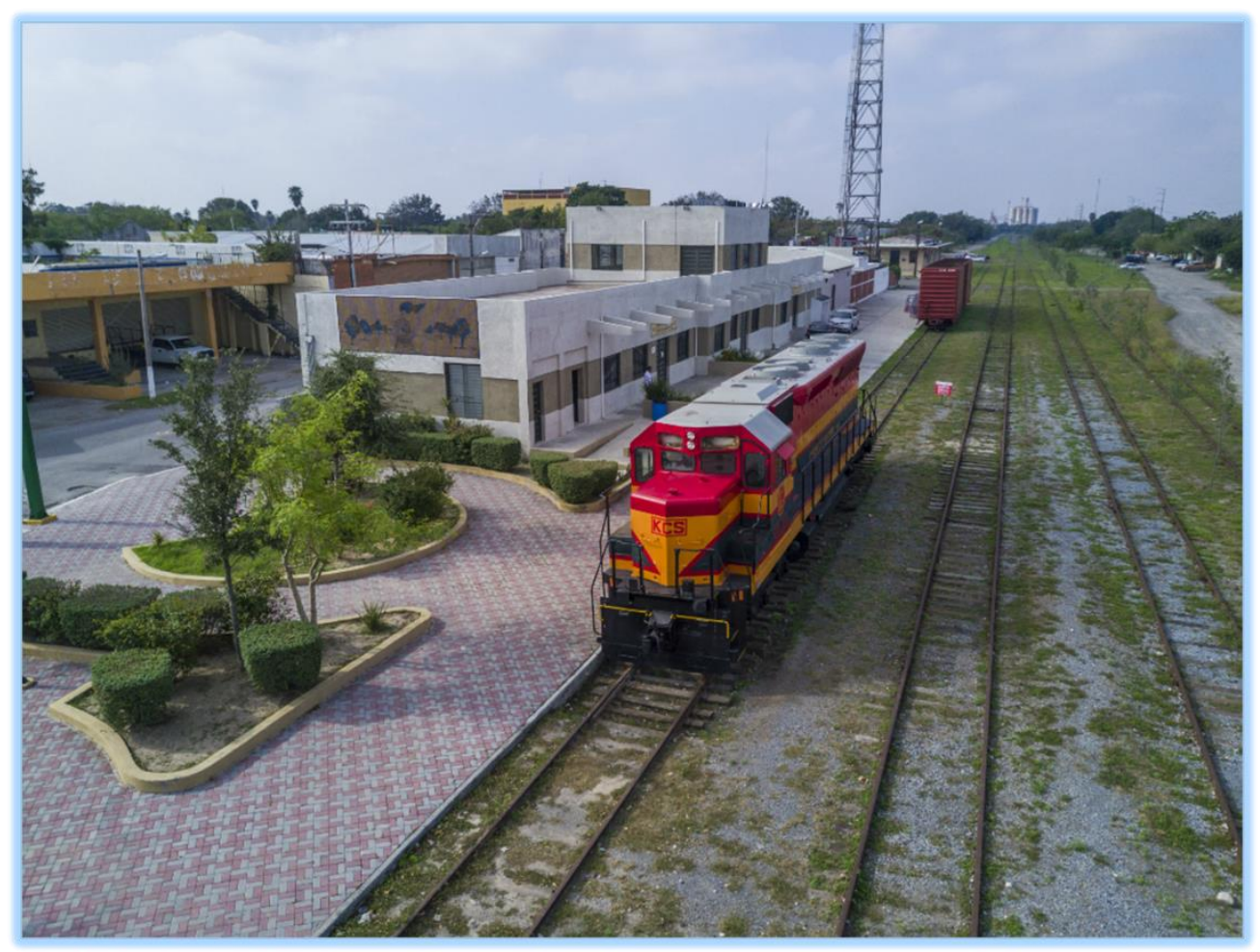

Fuente: Instituto Municipal de Planeación de Matamoros para el proyecto del CeCuBi (2021).

Finalmente, se propone como uno de los ejes articuladores del proyecto, la construcción de una ciclopista binacional que permita unir ambas ciudades en un circuito cultural, en la que el ciudadano tenga acceso a los recursos compartidos por ambos lados de la frontera. En el caso de Brownsville, se desarrollarán siete millas de ciclovías, mientras que en Matamoros constará de un parque lineal de 2,32 km, tal como se aprecia en la figura 9: 
Figura 9: West Rail Train

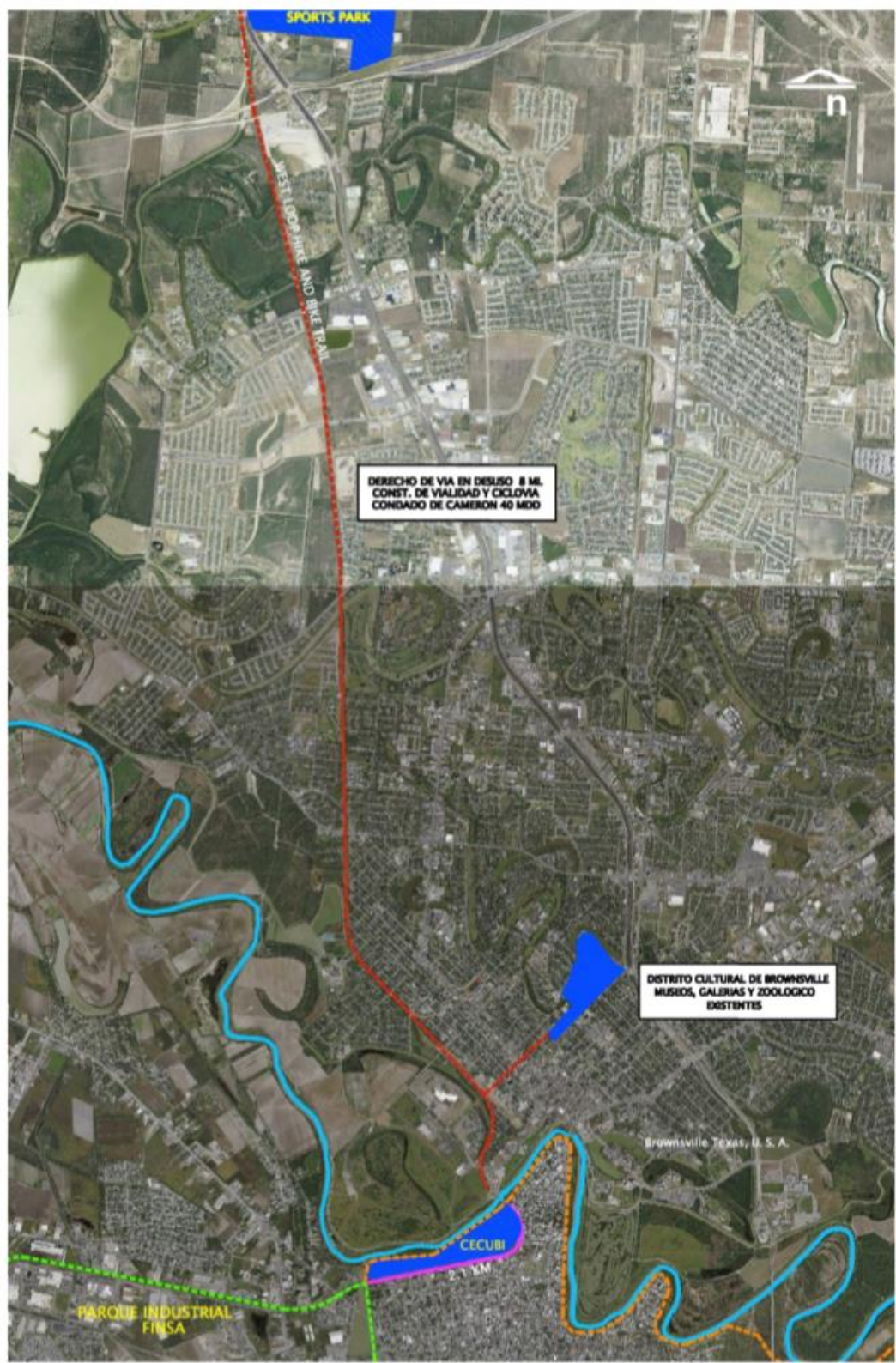

Fuente: Condado de Cameron e Instituto Municipal de Planeación de Matamoros para el proyecto del CeCuBi (2021).

A partir de todo lo anterior, es necesario comentar que ambos estudios de caso, además de estar estrechamente relacionados entre sí, obedecen a una transformación en la visión y la esencia misma de su existencia: un proyecto que se inició con un enfoque de espacios de flujos (Libramiento Ferroviario Brownsville-Matamoros) se ha transformado actualmente en un proyecto con enfoque de espacios de lugar, lo cual ha permitido rescatar la herencia histórica compartida por ambas ciudades, así como las dinámicas transfronterizas propias de un espacio en donde sus poblaciones conviven, intercambian y generan sus propios espacios culturales. 
La instrumentación del proyecto del $\mathrm{CeCuBi}$ ha contribuido a ampliar la perspectiva de cómo hacer la planificación transfronteriza, considerando la necesidad de reorientar los espacios de flujos, a partir de la remodelación y creación de nuevos espacios públicos que favorezcan las dinámicas transfronterizas locales de dos poblaciones que comparten lazos históricos y socioculturales muy estrechos. De esta manera, se ha fortalecido la generación de espacios de lugar que permitan, en última instancia, promover la cohesión espacial a partir de las dinámicas e influencia de las poblaciones de ambos lados de la frontera.

\section{Conclusiones y reflexiones finales}

Entre los resultados que se tienen prospectados de ambos proyectos (Proyecto Ferroviario Brownsville-Matamoros y $\mathrm{CeCuBi}$ ), y en general teniendo como base la visión que se desarrolló a partir del Plan de Instrumentación Estratégica, se puede mencionar que se prevé que con la instrumentación del $\mathrm{CeCuBi}$ disminuirán los tiempos de espera actuales para cruzar el puente internacional. Esto, debido a que se contempla que la empresa BMBC ejecute la ampliación y reconversión del puente ferroviario internacional B\&M para permitir el flujo a México sobre dicho puente con dos carriles y reorganizar el flujo hacia suelo estadounidense sobre el puente vehicular actual con cuatro carriles, incrementando los puntos de inspección disponibles (enfoque del espacio de flujos). Este será complementario al sistema de puentes internacionales de la zona, que incluye el Puente de Los Tomates, el Puente Nuevo, el Puente Lucio-Blanco, entre otros más.

A nivel binacional, mejorará la conectividad del sistema de puentes internacionales que forman parte del corredor carretero Mazatlán-Matamoros. La red de carreteras de México se enlaza con las carreteras interestatales I-37, I-10, I-35, que forman parte de los principales corredores carreteros en Estados Unidos, así como con el puerto marítimo de Brownsville, por lo que su ampliación consolidará a la región Brownsville-Matamoros como un punto estratégico en diversas rutas intermodales.

Se reducirá el congestionamiento vial actual entre Brownsville y Matamoros, ocasionado por las largas filas de espera en los puentes, que obstruyen y afectan el tránsito local. Asimismo, se mejorará el desarrollo urbano de la ciudad de Matamoros, ya que se habilitarán, por parte del municipio, las calles por las que se tendrá acceso al centro de Matamoros, así como la salida a las ciudades de Reynosa y Ciudad Victoria, con las avenidas Galena y Azcárraga. Adicionalmente, mejorará la calidad de vida de las poblaciones fronterizas, al dotarlas de espacios públicos de recreación y participación.

Es importante mencionar que los dos estudios de caso presentados a lo largo de este artículo constituyen obras referenciales en la frontera México-Estados Unidos. Mientras que el Proyecto de Libramiento Ferroviario fue el primero en su tipo después de más de cien años, el $\mathrm{CeCuBi}$ se ha consolidado como una de las primeras obras de infraestructura binacional en la frontera México-Estados Unidos en considerar el sector cultural como una estrategia 
para mejorar la calidad de vida de la población fronteriza, recuperar los espacios, promover la riqueza y trabajar por la valoración y conservación del legado histórico y artístico ferroviario de nuestro país. En este tenor, la relocalización de las vías del ferrocarril generó externalidades positivas (otros proyectos que se fueron sumando) que han llevado a un cambio en la visión del espacio.

A partir de la experiencia en la instrumentación de estos proyectos, y considerando que otras ciudades de la frontera México-Estados Unidos comparten la misma problemática, derivada de la convivencia urbano-ferroviaria, se están instrumentando otros proyectos, como el Libramiento Ferroviario Jerónimo-Santa Teresa, o el Proyecto Mission/Madero-Reynosa, los cuales están contemplando una visión integral basada en la experiencia de la RBM que incluya los procesos binacionales, con base en los espacios de flujo y de lugar.

Estos procesos de instrumentación resultan más eficaces debido a otra práctica exitosa obtenida a partir de los proyectos descritos en el presente artículo: la definición de un proceso de instrumentación de un proyecto de infraestructura binacional. A lo largo de las cuatro fases del proyecto, hay elementos que se mantienen presentes y que es necesario considerar y trabajar paralelamente, con la finalidad de lograr una instrumentación exitosa en cualquier punto de la frontera México-Estados Unidos. A ello se suma el trabajo y la cooperación de todos los participantes que se comprometieron a sacar adelante cada una de las actividades a lo largo de las cuatro fases de instrumentación del mismo.

A partir de los estudios de caso anteriores, se puede argumentar que la planeación transfronteriza en Brownsville y Matamoros ha dado algunos pasos para moverse de un enfoque de planeación de "espacios de flujos" a un enfoque de "espacios de lugar", basada en un espacio relacional que trata de enfatizar los lazos sociales y la memoria histórica, entre otros factores relevantes.

Finalmente, una cosa nos queda clara: el trabajo de planeación transfronteriza no se queda aquí. Se requiere la combinación entre conocimiento y experiencia pero, sobre todo, se requiere de una visión a largo plazo que permita generar planes que atiendan, por un lado, el dinamismo de la región (espacio de flujos) sin que ello represente una merma en la dinámica binacional (espacio relacional) propia de cada punto de la frontera México-Estados Unidos.

Ambos estudios de caso demostraron que una condición necesaria para la planeación transfronteriza es el generar confianza y reciprocidad entre todos los participantes de los procesos de instrumentación, así como de las poblaciones de ambos lados de la frontera México-Estados Unidos. Estos casos dan cuenta de que con pequeñas iniciativas se puede generar esa confianza para posteriormente pensar en proyectos de mayor alcance e impacto. Lo importante en la planeación transfronteriza es comenzar con un plan o proyecto que tenga una alta probabilidad de éxito, basada en que todos los actores obtengan un beneficio común.

Los aprendizajes de esos proyectos detonadores son fundamentales para poder pensar en proyectos de mayor escala, alcance y más complejos. Lo fundamental es crear esas 
comunidades epistémicas transfronterizas, cuya función sea facilitar la discusión y el diálogo para desarrollar marcos de acción compartidos y procesos de planeación. El aporte más importante de este grupo de actores fue elaborar un mapa de ruta del proceso que no existía, y que ahora ese mapa permite visualizar y facilitar la toma de decisiones no solo en la RMB, sino en toda la frontera de México-Estados Unidos.

Finalmente, es importante señalar que los proyectos de movilidad son piezas claves del desarrollo de las regiones transfronterizas no exclusivamente en la frontera México-Estados Unidos, sino que es posible hallar proyectos de este tipo en otras regiones de América Latina, como es el caso del ferrocarril trasandino en la frontera que comparten Argentina y Chile (Lacoste y Jiménez, 2013).

\section{Referencias bibliográficas}

Agnew, J. (1994). The territorial trap: the geographical assumptions of international relations theory. Review of International Political Economy, 1(1), 53-80.

Agnew, J. (2015). Place and Politics: The Geographical Mediation of State and Society. Nueva York: Routledge.

Alarcón Cantú, E. (2000). Estructura urbana en ciudades fronterizas: Nuevo Laredo-Laredo, Reynosa-McAllen, Matamoros-Brownsville. México: El Colegio de la Frontera Norte.

Alegría Olazábal, T. (1992). Desarrollo urbano en la frontera México-Estados Unidos. México: Conaculta.

Alegría, Olazábal T (2009), Metrópolis transfronteriza. Revisión de la hipótesis y evidencias de Tijuana, México, y San Diego, Estados Unidos. Tijuana-México: El Colegio de la Frontera Norte / Porrúa

Allmendinger, P. y Tewdwr-Jones, M. (2005). Planning Futures: New Directions for Planning Theory. Nueva York: Routledge.

Álvarez, R. (2012). Borders and bridges: Exploring a new conceptual architecture for (USMexico) border studies. The Journal of Latin American and Caribbean Anthropology, $17(1), 24-40$.

Aspe, P. (1993). Economic Transformation the Mexican Way. Cambridge, Mass.: MIT Press.

Auge, M. (2008). Non-places: An Introduction to Supermodernity. Nueva York: Verso.

Blatter, J. (2004). From 'spaces of place' to 'spaces of flows'? Territorial and functional governance in cross-border regions in Europe and North America. International Journal of Urban and Regional Research, 28(3), 530-548. 
Brunet-Jailly, E. (2005). Theorizing borders: An interdisciplinary perspective. Geopolitics, 10(4), 633-649. DOI: 10.1080/14650040500318449

Bryson, J. M. (2011). Strategic Planning for Public and Nonprofit Organization. San Francisco: Jossey-Bass.

Castells, M. (1989). The Informational City: Information Technology, Economic Restructuring, and the Urban-Regional Process. Oxford: Blackwell.

Castells, M. (1996). The Rise of the Network Society (Vol. 12). Malden: Blackwell Publishers.

Condado de Cameron. (2012). Plan de Instrumentación Estratégica del Condado de Cameron, Texas, y el Municipio de Matamoros, Tamaulipas.

Cresswell, T. (2015). Place: An Introduction. Malden: Wiley Blackwell.

De las Fuentes, A. (2007). Proyecto Ferroviario Brownsville-Matamoros: retos y oportunidades políticas en la instrumentación de proyectos binacionales, y su impacto en la frontera México-Estados Unidos, a partir de un estudio de caso (Tesis para obtener el grado de doctor en Ciencia Política). Facultad de Ciencias Políticas y Sociales, Universidad Nacional Autónoma de México, México, D. F., Ciudad Universitaria, julio.

De las Fuentes, A (2021). Minutas de trabajo del Grupo Técnico Binacional para los proyectos: Libramiento Ferroviario Brownsville-Matamoros y Centro Cultural Binacional.

De Mattos, C. A. (2010). Globalización y metamorfosis metropolitana en América Latina: de la ciudad a lo urbano generalizado. Revista de Geografía Norte Grande, (47), 81104.

Denhardt, J. V. y Denhardt, R. B. (2003). The New Public Service: Serving not Steering. Nueva York: M. E. Sharp.

Friedmann, J. (2005). Globalization and the emerging culture of planning. Progress in Planning, 64(3), 183-234.

Fuentes, C. M. y Fuentes, N. A. (2004). Desarrollo económico en la frontera norte de México: de las políticas nacionales de fomento económico a las estrategias de desarrollo económico local. Araucaria. Revista Iberoamericana de Filosofía, Política y Humanidades, $\quad 5(11), \quad 0 . \quad$ Recuperado de https://www.redalyc.org/articulo.oa?id=28211507

Garza, G. (2005). La urbanización de México en el siglo XX. México: El Colegio de México. 
Guillén López, T. (1995). El municipio y el desarrollo social de la frontera norte. México: El Colegio de la Frontera Norte/Friedrich Ebert. Recuperado de https://www.researchgate.net/publication/323457824_El_municipio_y_el_desarroll o_social_de_la_frontera_norte

Healey, P. (1997). Collaborative Planning: Shaping Places in Fragmented Societies. Nueva York: Macmillan International Higher Education.

Healey, P. (2007). Urban Complexity and Spatial Strategies: Towards a Relational Planning for our Times. Nueva York: Routledge.

Hambleton, R. y Gross, S. (eds.) (2007). Governing Cities in a Global Era: Urban Innovation, Competition, and Democratic Reform. Nueva York: Palgrave Macmillan.

Harvey, D. (2006). Spaces of Global Capitalism: Towards a Theory of Uneven Geographical Development. Nueva York: Verso.

Hooghe, L. y Marks, G. (2001). Multilevel Governance and European Integration. Nueva York: Rowman \& Littlefield Publishers.

Instituto Municipal de Planeación de Matamoros (2013-2016). Sección Vivienda. IMPLAN [sitio web]. Recuperado de http://www.implanmatamoros.gob.mx/sectorsocial/vivienda.asp

INEGI (2020). Estadística mensual del Programa de la Industria Manufacturera, Maquiladora y de Servicios de Exportación (IMMEX). Recuperado de: https://www.inegi.org.mx/contenidos/programas/immex/tabulados/ori/immex_mens _entymun.xlsx

Instituto Mexicano de Ejecutivos de Finanzas (IMEF) (1986). Maquiladoras. Su estructura y operación. México: Publicaciones IMEF.

Innes, J. E., y Booher, D. E. (2010). Planning with Complexity: An Introduction to Collaborative Rationality for Public Policy. Nueva York: Routledge.

Kaufman, J. L. y Jacobs, H. M. (1987). A public planning perspective on strategic planning. Journal of the American Planning Association, 53(1), 23-33.

Lacoste Gargantini, P. y Jiménez Cabrera, D. (2013). Transporte internacional y actores subnacionales de Mendoza y la resurrección del ferrocarril transandino entre Argentina y Chile. Si Somos Americanos. Revista de Estudios Transfronterizos, 13(1), 65-92.

Laine, J. P. (2016). The multiscalar production of borders. Geopolitics, 21(3), 465-482. DOI: 10.1080/14650045.2016.1195132 
Lara Pacheco, R. F. y Cerqueira Torres, O. M. (2017). Las ciudades en la gobernanza global multinivel: una aproximación teórica. Si Somos Americanos. Revista de Estudios Transfronterizos, 17(2), 43-75.

Lascurain, M. (2018). Teorías de regímenes internacionales: el caso del recurso agua en el régimen ambiental México-Estados Unidos. Si Somos Americanos. Revista de Estudios Transfronterizos, 18(2), 128-158.

Lefebvre, H. (1974). The Production of Space. Cambridge, Mass.: Blackwell.

Lindblom, C. E. (1959). The science of" muddling through". Public Administration Review, $9(2), 79-88$.

Lorey, D. (1993). United States-Mexico Border Statistics Since 1900: 1990 Update. Los Angeles: UCLA.

Massey, D. (2005). For Space. Thousand Oaks: Sage.

Newman, D. (2006). The lines that continue to separate us: Borders in our 'borderless' world. Progress in Human Geography, 30(2), 143-161.

North American Development Bank (NADBANK) (2016). Análisis de los proyectos de puertos fronterizos en la frontera México-Estados Unidos. [En línea]. Recuperado de https://www.nadb.org/uploads/files/december_2019_port_of_entry_study_final_rep ort_spanish_version_clean.pdf

Oliveras González, X. (2015). Estrategias de marketing territorial en una región transfronteriza: Tamaulipas-Texas. Si Somos Americanos. Revista de Estudios Transfronterizos, 15(2), 97-122.

Peña, S. (2005). Recent developments in urban marginality along Mexico's northern border. Habitat International, 29(2), 285-301.

Peña, S. (2011). Regímenes de planificación transfronteriza: México-Estados Unidos. Región y sociedad, 23(50), 115-151.

Peña, S. (2021). Movilidad transfronteriza, planeación y gobernanza en la frontera MéxicoEstados Unidos: procesos y resultados. Gestión y Política Pública, 30(1), 1-30.

Quintero, C. y De la O, E. (1995). Trayectorias laborales y estabilidad en las maquiladoras de Matamoros y Tijuana. Frontera Norte, 7(13), 67-91.

Quintero, C. (2005). Los claroscuros de la industria maquiladora. Los casos de Tijuana y Matamoros. En C. Arce Macías y A. Ziccardi Contigiani (coords.), Ciudades del siglo XXI: ¿competitividad o cooperación? (pp. 451-484). México: CIDE-Miguel Ángel Porrúa. 
Sassen, S. (2001). The Global City: New York, London, Tokyo. Nueva Jersey: Princeton University Press.

Sassen, S. (2006). Cities in a World Economy. Thousand Oaks, Cal.: Pine Forgess Press.

Scott, J. W. (1999). European and North American contexts for cross-border regionalism. Regional Studies, 33(7), 605-617.

Secretaría de Comunicaciones y Transportes (SCT) (2016). Memoria documental. Libramiento Ferroviario y Puente Internacional Matamoros-Brownsville. México: SCT. Recuperado de https://www.sct.gob.mx/fileadmin/Transparencia/rendicionde-cuentas/MD/63_MD.pdf

Soja, E. W. (1989). Postmodern Geographies: The Reassertion of Space in Critical Social Theory. Nueba York: Verso.

Soja, E., (1996). Thirdspace: Journeys to Los Angeles and Other Real-and-Imagined Places. Malden, MA: Blackwell.

Sohn, C. (2014). Modelling cross-border integration: The role of borders as a resource. Geopolitics, 19(3), 587-608.

Staudt, K., Fuentes, C. M. y Monarrez-Fragoso, J. (eds.). (2010). Cities and Citizenship at the US-Mexico Border: The Paso del Norte Metropolitan Region. Nueva York: Palgrave.

Swyngedouw E. (2004). Scaled geographies. Nature, place, and the politics of scale. En E. Sheppard y R. McMaster (eds.), Scale and Geographic Inquiry: Nature, Society and Method (pp. 129-153). Oxford y Cambridge: Blackwell.

Trejo Nieto, A. (2013). Desafíos de la competitividad en la frontera norte de México en el marco del reajuste global. Frontera Norte, 25(50), 213-221.

Tuan, Y. F. (1977). Space and Place: The Perspective of Experience. Minneapolis: University of Minnesota Press.

Van Houtum, H. (2010). Mapping transversal borders: Towards a choreography of space. En B. Riccio y C. Brambilla (eds.), Transnational Migration, Cosmopolitanism and Dislocated Borders (pp. 119-138). Rimini: Guaraldi.

Venegas San Martín, F. (2019). Pensar la integración desde los márgenes: la importancia y desafíos de la dimensión subestatal en América Latina desde la experiencia chilenoargentina. Si Somos Americanos. Revista de Estudios Transfronterizos, 19(2), 69-88.

Virilio, P. (2006). Speed and Politics. Cambridge, Mass.: MIT Press.

Yin, R. K. (1994). Case Study Research: Design and Methods. Thousand Oaks: Sage. 